\title{
Perancangan Sistem Online Monitoring Pembebanan Transformator Distribusi Menggunakan Mikrokontroller
}

\author{
Indar Chaerah Gunadin \\ Departemen Teknik Elektro, \\ Fakultas Teknik, \\ Universitas Hasanuddin \\ *indarcg@gmail.com \\ Herianto \\ Departemen Teknik Elektro, \\ Fakultas Teknik, \\ Universitas Hasanuddin
}

\author{
Zity Aida Bahtiar \\ Departemen Teknik Elektro, \\ Fakultas Teknik, \\ Universitas Hasanuddin
}

\author{
Muhammad Al Izza Hizbullah \\ Departemen Teknik Elektro, \\ Fakultas Teknik, \\ Universitas Hasanuddin
}

\begin{abstract}
Abstrak - Electric energy is basically one of the main needs used in various activities in the community. In the distribution of electricity energy is required a reliable system so that the continuity of electricity energy that reaches consumers can be guaranteed well. One of the systems that needs to be maintained is the system related to distribution in addition to transmission and power generation systems. Reliability and quality of power must be maintained properly. Transformer damage is usually affected by overload which can harm the transformer itself as well as transformer insulation. A hot transformer can cause a short circuit that can cause the transformer to explode, so that the damage to the transformer can shorten the life of use both in terms of tools and oil. Electricity monitoring system has been widely implemented with the installation of electric measuring instruments on the transformer panel before entering the load. This research aims to build a prototype transformer monitoring module in real time based on the Internet of Things. This research is in line with Unhas research plan related to innovations in the field of Energy and the development of smart grid systems that can optimize the utilization of various new and renewable sources that vary, while being able to control the efficient use patterns of electricity energy on the downstream side through the protocol of informatics technology systems that have advanced today.
\end{abstract}

Keywords: monitoring, power quality, transformer, distribution, harmonization

\section{PENDAHULUAN}

Energi listrik pada dasarnya merupakan salah satu kebutuhan utama yang digunakan dalam berbagai kegiatan di lingkungan masyarakat. Perguruan tinggi juga menggunakan energi listrik dalam kegiatan belajar dan mengajar maupun dalam kegiatan perkantoran. Faktor yang dapat mempengaruhi kualitas dari energi listrik adalah tegangan, arus dan daya listrik. Kebutuhan pasokan energi listrik akan terus meningkat seiring dengan pertumbuhan populasi manusianya maupun tingkat perkembangan teknologinya. Hal ini yang menyebabkan energi listrik menjadi peranan penting dalam kehidupan. Namun, seiring bertambahnya tingkat kebutuhan energi listrik menyebabkan timbulnya masalah dalam keterbatasan sumber daya alam dalam pemenuhan rotoc listrik itu sendiri. Berbagai upaya dalam menangani permasalahan tersebut hingga penelitiannya mucul gagasan dengan mengimplementasikan sistem monitoring sebagai salah satu cara yang efisien dalam pemantauan dan pemeliharaan transformator.

Kerusakan transformator biasanya dipengaruhi beban berlebih yang dapat membahayakan transformator itu sendiri maupun isolasi transformator. Transformator yang panas dapat menimbulkan short circuit yang dapat mengakibatkan transformator meledak, sehingga kerusakan transformator dapat memeperpendek usia pemakaian baik dari segi alat maupun minyaknya. Sistem monitoring besaran listrik sudah banyak dilimplementasikan dengan pemasangan alat ukur listrik pada panel transformator sebelum masuk ke beban. Cara ini dianggap kurang effisiensi, dimana untuk memonitoringnya harus dilakukan secara langsung ke lokasi pemasangan alat ukur. Hal ini yang menyebabkan perlu adanya suatu sistem monitoring yang dapat menyimpan data sekaligus menampilkannya dalam kondisi online, serta mampu memberikan informasi yang dapat dijadikan sebagai referensi analisa sistem tenaga listrik. Sistem penyaluran tenaga listrik dari pembangkit tenaga listrik ke konsumen (beban), merupakan hal penting untuk dipelajari. Mengingat penyaluran tenaga listrik ini, prosesnya melalui beberapa tahap, yaitu dari 


\section{Perancangan Sistem Online Monitoring Pembebanan Transformator Distribusi Menggunakan Mikrokontroller}

pembangkit tenaga listrik penghasil energi listrik, disalurankan ke jaringan transmisi (SUTET) langsung ke gardu induk. Dari gardu induk tenaga listrik disalurkan ke jaringan distribusi primer (SUTM), dan melalui gardu distribusi langsung ke jaringan distribusi sekuder (SUTR), tenaga listrik dialirkan ke konsumen. Dengan demikian sistem distribusi tenaga listrik berfungsi membagikan tenaga listrik kepada pihak pemakai melalui jaringan tegangan rendah (SUTR), sedangkan suatu saluran transmisi berfungsi untuk menyalurkan tenaga listrik bertegangan ekstra tinggi ke pusat-pusat beban dalam daya yang besar (melalui jaringan distribusi) [1].

Sistem Distribusi merupakan bagian dari sistem tenaga listrik. Sistem distribusi ini berguna untuk menyalurkan tenaga listrik dari sumber daya listrik besar (Bulk Power Source) sampai ke konsumen. Jadi fungsi distribusi tenaga listrik adalah; 1) pembagian atau penyaluran tenaga listrik ke beberapa tempat (pelanggan), dan 2) merupakan sub sistem tenaga listrik yang langsung berhubungan dengan pelanggan, karena catu daya pada pusat-pusat beban (pelanggan) dilayani langsung melalui jaringan distribusi [2].

\section{TEORI DASAR}

Penggunaan komputer dimasa mendatang mampu mendominasi pekerjaan manusia dan mengalahkan kemampuan komputasi manusia seperti mengontrol peralatan elektronik dari jarak jauh menggunakan media internet, Internet of Things (IoT) memungkinkan pengguna untuk mengelola dan mengoptimalkan elektronik dan peralatan listrik yang menggunakan internet.[4] Internet of Things atau dikenal juga dengan IoT, merupakan sebuah konsep yang bertujuan untuk memperluas manfaat dari konektivitas internet yang tersambung secara terusmenerus. Adapun penggunaannya seperti berbagi data, kontrol jarak jauh, dan sebagainya, termasuk benda hidup yang semuanya tersambung ke jaringan lokal dan global melalui sensor yang tertanam dan selalu aktif.

Trafo Distribusi adalah merupakan suatu komponen yang sangat penting dalam penyaluran tenaga listrik dari gardu distribusi kekonsumen. Kerusakan pada Trafo Distribusi menyebabkan kontiniutas pelayanan terhadap konsumen akan terganggu (terjadi pemutusan aliran listrik atau pemadaman). Pemadaman merupakan suatu kerugian yang menyebabkan biaya-biaya pembangkitan akan meningkat tergantung harga KWH yang tidak terjual. Pemilihan rating Trafo Distribusi yang tidak sesuai dengan kebutuhan beban akan menyebabkan efisiensi menjadi kecil, begitu juga penempatan lokasi Trafo Distribusi yang tidak cocok mempengaruhi drop tegangan ujung pada konsumen atau jatuhnyaturunnya tegangan ujung saluran/konsumen.[5]

Monitoring adalah proses pengumpulan dan analisis informasi berdasarkan indikator yang ditetapkan secara sistematis dan kontinu tentang kegiatan program sehingga dapat dilakukan tindakan koreksi untuk penyempurnaan program kegiatan itu selanjutnya. pemantauan yang dapat dijelaskan sebagai kesadaran (awareness) tentang apa yang ingin diketahui, pemantauan berkadar tingkat tinggi dilakukan agar dapat membuat pengukuran melalui waktu yang menunjukkan pergerakan ke arah tujuan atau menjauh dari itu [5].

Mikrokontroler adalah sistem mikroprosesor lengkap dengan piranti elektronik berupa Integrated Circuit (IC) yang memiliki kemampuan manipulasi data (informasi) berdasarkan suatu urutan instruksi (program) yang di buat oleh programmer dimana di dalamnya sudah terdapat Electricaly Erasable Programmable Read Only Memory (EEPROM), Central Processing Unit (CPU), Random Acces Memory (RAM), , I/O, Timer dan peralatan internal lainnya yang sudah saling terhubung. Mikrokontroler pada dasarnya adalah komputer dalam satu chip, yang di dalamnya terdapat mikroprosesor, jalur Input/Output (I/O), memori dan perangkat pelengkap lainnya. Pada PC kecepatan mikroprosesor yang digunakan saat ini telah mencapai orde $\mathrm{GHz}$, sedangkan kecepatan operasi mikrokontroler pada umumnya berkisar antara $1-16 \mathrm{MHz}$. Oleh karena itu kecepatan pengolahan data pada mikrokontroler lebih rendah jika dibandingkan dengan PC. Begitu juga kapasitas RAM dan ROM pada PC yang bisa mencapai orde Gbyte, dibandingkan dengan mikrokontroler yang hanya berkisar pada orde byte/Kbyte. Penggunaan mikrokontroler sudah banyak ditemui dalam berbagai peralatan elektronik, seperti telepon digital, microwave oven, dan lain-lain. Mikrokontroller juga dapat digunakan dalam dunia industri seperti: sistem kendali, otomasi dan lain-lain.

Secara langsung menggantikan Arduino dan ditambah lagi dengan kemampuannya untuk mensupport koneksi wifi secara langsung. Ada beberapa jenis ESP8266 yang dapat ditemui dipasaran, namun yang paling mudah didapatkan di Indonesia adalah type ESP-01,07,dan 12 dengan fungsi yang sama perbedaannya terletak pada GPIO pin yang disediakan. Tegangan kerja ESP-8266 adalah sebesar $3.3 \mathrm{~V}$, sehingga untuk penggunaan mikrokontroler tambahannya dapat menggunakan board arduino yang memiliki fasilitas tengangan sumber $3.3 \mathrm{~V}$, akan tetapi akan lebih baik jika membuat secara terpisah level shifter untuk komunikasi dan sumber tegangan untuk wifi module ini. Dalam mengoperasikan ESP8266(WEMOS) harus menggunakan software untuk memasukkan program, program yang digunakan pada arduino adalah bahasa C. Berikut fungsi dan penampakan software Arduino IDE: 


\section{Perancangan Sistem Online Monitoring Pembebanan Transformator Distribusi Menggunakan Mikrokontroller}

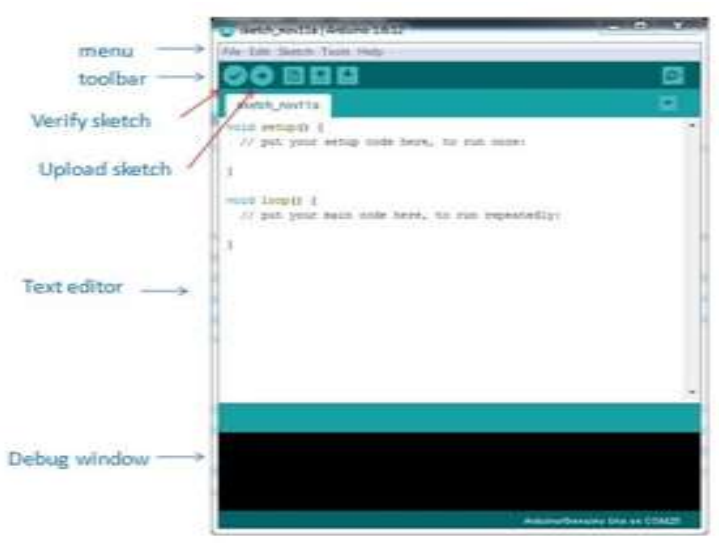

Gambar 1. Software Arduino IDE

Solenoid Door Lock adalah salah satu solenoid pengunci otomatis yang difungsikan khusus sebagai solenoid untuk pengunci pintu. Solenoid Door Lock ini membutuhkan tegangan supply $12 \mathrm{v}$, sistem kerja solenoid pengunci pintu ini adalah NC (Normally Close). Katup solenoid akan tertarik jika ada tegangan dan sebaliknya katup solenoid akan memanjang jika tidak ada tegangan [10].

PZEM-004T adalah sensor yang dapat digunakan untuk mengukur tegangan, arus, frekuensi dan daya aktif yang dapat dihubungkan melalui ESP8266 ataupun platform opensource lainnya. Dimensi fisik dari papan PZEM-004T adalah 3,1 × 7,4 $\mathrm{cm}$. Modul pzem-004t dibundel dengan kumparan trafo arus diameter $3 \mathrm{~mm}$ yang dapat digunakan untuk mengukur arus maksimal sebesar 100A.

Modul ini terutama digunakan untuk mengukur tegangan AC, arus, daya aktif, frekuensi, faktor daya dan energi aktif, modul tanpa fungsi tampilan, data dibaca melalui interface TTL. Interface TTL dari modul ini adalah interface pasif, membutuhkan catu daya eksternal $5 \mathrm{~V}$, yang berarti ketika berkomunikasi, keempat port harus terhubung $(5 \mathrm{~V}, \mathrm{RX}, \mathrm{TX}, \mathrm{GND})$ jika tidak ia tidak dapat berkomunikasi.

Deskripsi fungsi PZEM-004T yaitu :

1. Tegangan
a. Rentang pengukuran :80 $260 \mathrm{~V}$
b. Resolusi : $0.1 \mathrm{~V}$
c. Ketepatan ukur : $0.5 \%$

2. Arus
a. Rentang pengukuran : 0 10A (PZEM-004T-
10A); 0 100A (PZEM-004T-100A).
b. Mulai mengukur arus : 0.01A (PZEM-004T-
10A); 0.02A (PZEM-004T 100A).
c. Resolusi: 0.001A.
d. Ketepatan ukur: $0.5 \%$.
a. Rentang pengukuran : 0 2.3kW (PZEM-004T-
10A); 0 23kW (PZEM-004T-100A).
b. Mulai mengukur daya : $0.4 \mathrm{~W}$.
c. Resolusi: $0.1 \mathrm{~W}$.
a. Rentang pengukuran: $0.00 \sim 1.00$.
b. Resolusi: 0.01 .
c. Ketepatan ukur : $1 \%$.

3. Daya

4. Faktor daya

\section{Frekuensi}

a. Rentang pengukuran : $45 \mathrm{~Hz} \sim 65 \mathrm{~Hz}$.

b. Resolusi: $0.1 \mathrm{~Hz}$.

c. Ketepatan ukur : $0.5 \%$.

6. Energi

a.Rentang pengukuran : 0 9999.99kWh.

b. Resolusi : $1 \mathrm{Wh}$.

c. Ketepatan ukur : $0.5 \%$.

d. Reset energi: gunakan perangkat lunak untuk mereset.

7. Alarm over power

Batas daya aktif dapat diatur, bila daya aktif yang diukur melebihi batas, ia dapat dilepas. Berikut merupakan gambar dari PZEM-004I.

\section{METODE PENELITIAN}

Untuk Mendapatkan rancang bangun alat monitoring daya maka dibutuhkan perancangan rakitan, pengukuran, dan pengujian. Berikut merupakan alur penelitian yang dilakukan.

Perancangan dan pembuatan sistem dibedakan atas dua perancangan yaitu perancangan perangkat keras (hardware) dan perancangan perangkat lunak (software). Gambar 2 menunjukkan flowchart atau diagram alir perancangan sistem tersebut. Alur kerja dari sistem tersebut dimulai dari pengecekan apakah user mengirimkan perintah untuk menerima input dari tombol atau tidak. Ketika tamu atau seseorang datang dan menekan tombol, buzzer akan berbunyi satu kali dan secara bersamaan program akan mengambil gambar kemudian menyimpan di $S D$ Card dan secara otomatis mengirimkan pemberitahuan ke user melalui Chat Bot Telegram beserta gambar dari tamu atau seseorang tersebut. Sedangkan jika user mengirimkan perintah untuk mengaktifkan sensor PIR, maka kamera akan standby untuk mengambil gambar jika gerakan terdeteksi, dan secara bersamaan mengirimkan pemberitahuan serta gambar ke user melalui Chat Bot.

Dari hasil penelitian perangkat keras dan pemrograman maka dapat dilakukan perancangan alat. Setelah itu dapat dilakukan pengaplikasian sensor PZEM-004T yang dikombinasikan dengan modul wifi ESP8266 (WEMOS) untuk memonitoring tegangan, arus, frekuensi, konsumsi daya dan pembayaran berbasis internet. Pengujian pada alat sendiri meliputi pengujian keakuratan pemgukuran dan komunikasi antar alat. 


\section{Perancangan Sistem Online Monitoring Pembebanan Transformator Distribusi Menggunakan Mikrokontroller}

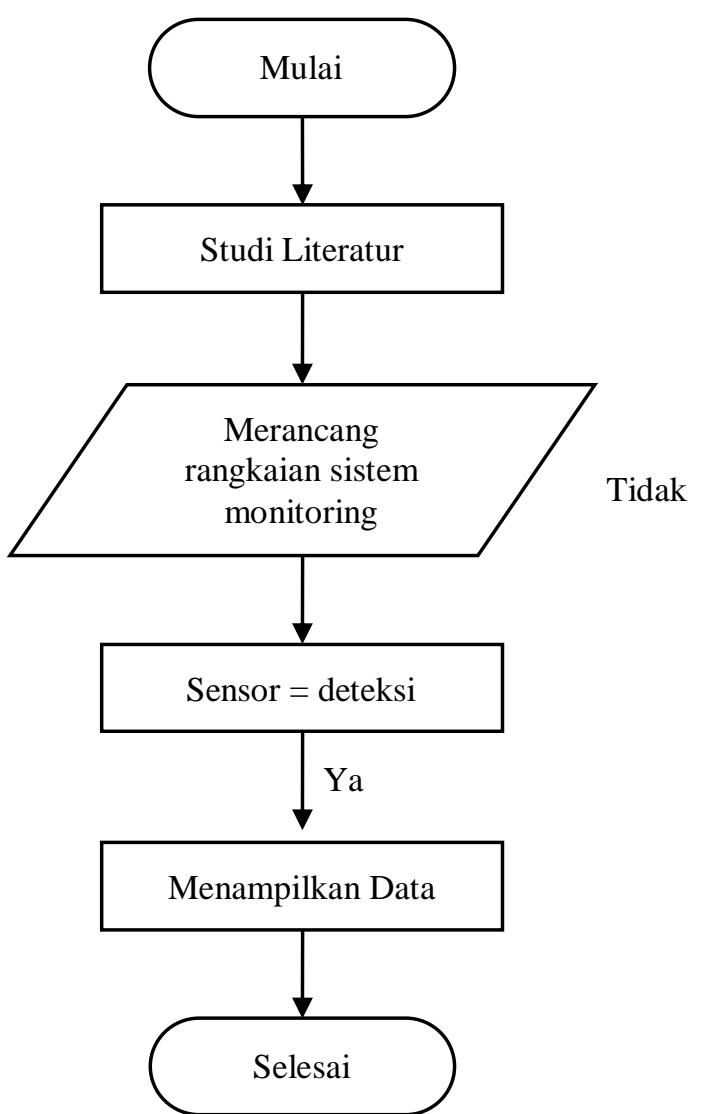

Gambar 2. Diagram alir perancangan sistem secara umum

Pada prinsipnya alat ini menggunakan sensor PIR yang digunakan untuk mendeteksi adanya gerakan, kamera raspberry pi yang berfungsi mengambil gambar ketika seseorang atau tamu berada didepan pintu rumah dan solenoid door lock sebagai pengunci pintu yang dapat dikendalikan. Komponen-kompenen tersebut kemudian dihubungkan dengan raspberry pi. Gambar dan informasi kemudian akan dikirim ke smartphone dalam bentuk chat melalui aplikasi telegram, blok diagram sistem seperti pada Gambar 3.

Alur kerja system yang digunakan adalah CT dipasangkan ke jaringan atau beban yang akan dimonitoring sebagai input arus ke PZEM-004T dan PZEM-004T juga membutuhkan input tegangan yang terhubung langsung ke tengangan dari jala jala PLN, PZEM-004T dihubungkan ke ESP8266 (WEMOS) menggunakan jumper. Setelah itu input tersebut di kirim ke halaman web yang sudah dirancang dan bisa diakses melalu smartphone ataupun computer yang terhubung dengan internet, kemudian web menampilkan hasil dari inputan tersebut sehingga user dapat memonitoring. Informasi yang ditampilkan adalah tegangan, arus, frekuensi, konsumsi daya dan pembayaran daya dalam waktu 1 bulan.

Setelah perancangan dan pembuatan alat maka langkah selanjutnya ialah menguji dan menganalisa alat tersebut. Pengujian ini bertujuan untuk mengetahui komunikasi antar komponen, nilai error, validasi data dan kekurangan apa saja yang harus dibenahi pada alat. Pengujian PZEM-004T

Pada proses pengujian PZEM-004T terbagi atas dua yaitu :

Pengujian tegangan pada PZEM-004T dilakukan dengan cara menghubungkan PZEM-004T ke ESP8266 untuk mengukur tegangan dan hasil dari pengukuran dibandingkan dengan hasil yang di dapatkan dengan menggunakan voltmeter.

Pengujian arus pada PZEM-004T dilakukan dengan cara menghubungkan PZEM-004T ke ESP8266 untuk mengukur arus dan hasil dari pengukuran dibandingkan dengan hasil yang di dapatkan dengan menggunakan amperemeter.

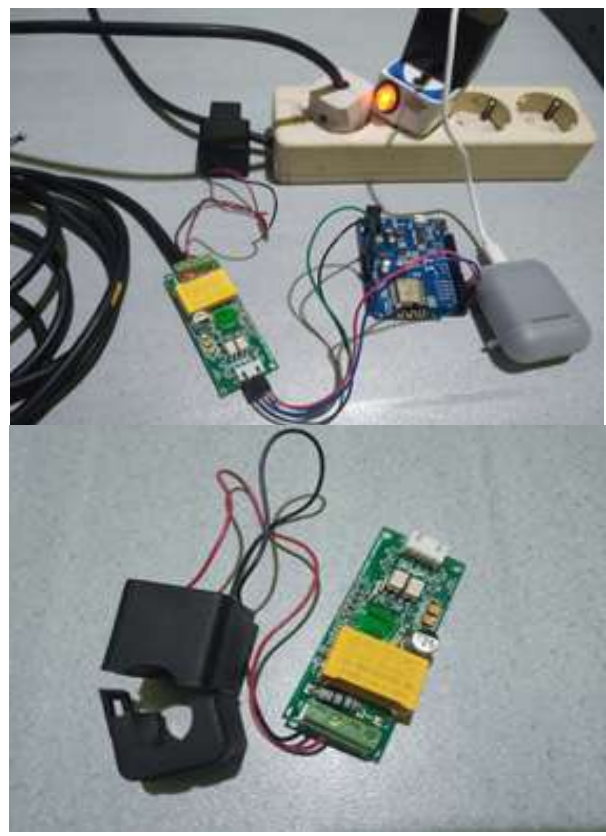

Gambar 3. Pengujian PZEM-004T

Pada tahap ini pengujian ESP8266 dilakukan unutk mengecek komunikasi antar ESP8266 dengan software ARDUINO IDE dengan cara memberikan perintah mudah atau sederhana ke ESP8266. Yaitu memberikan perintah kedip unutk led yang berada pada wemos. Seperti pada gambar.

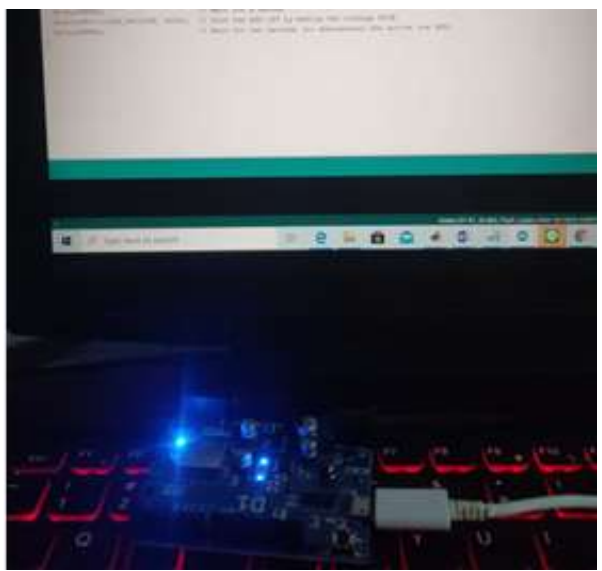

Gambar 4. Pengujian ESP8266 (WEMOS) 


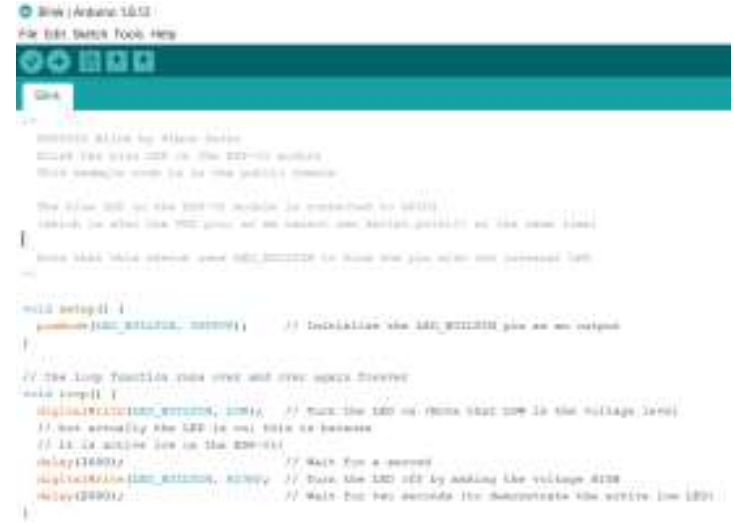

Gambar 5. Sintax Programming

Pengujian Aplikasi Blynk

Pada tahap ini dilakukan pengujian aplikasi android blynk yang dapat mengendalikan atau memberikan perintah ke suatu sensor untuk mereset kembali data yang ditampilkan pada grafik.

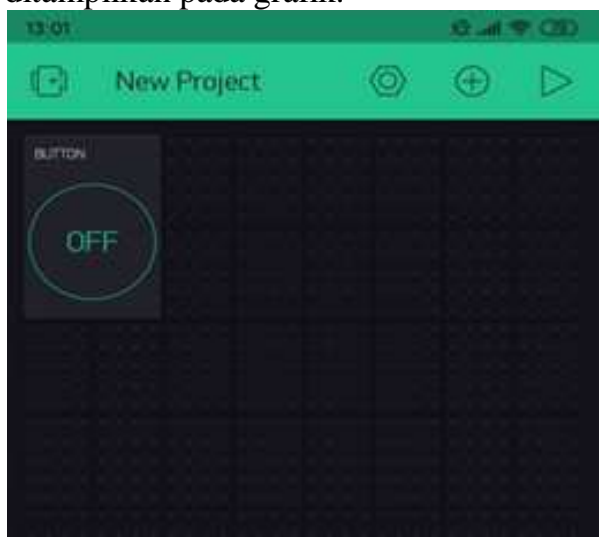

Gambar 6. Pengujian Aplikasi Blynk

Pengujian keseluruhan alat dengan cara menggabungkan seluruh komponen yang akan digunakan meliputi PZEM-004T, ESP8266 dan juga software untuk perintah yaitu Arduino Ide dan software untuk menampilkan grafik yaitu blynk.

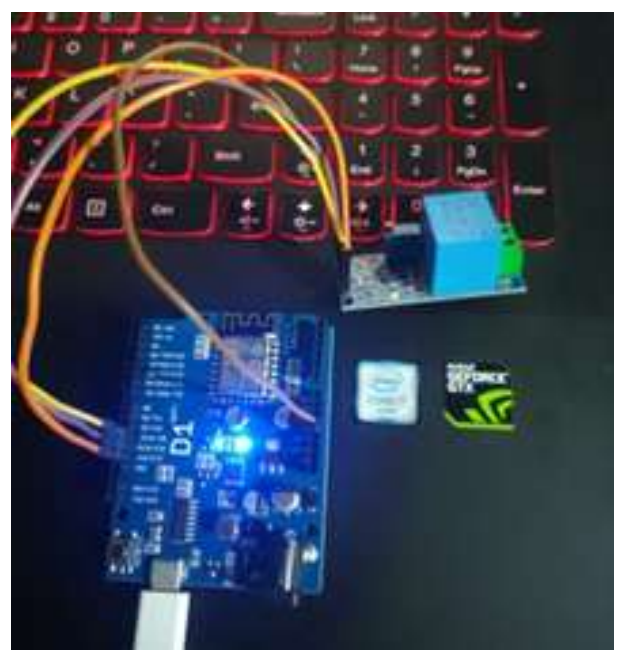

Gambar 7 Pengujian Keseluruhan Sistem

\section{KESIMPULAN}

Online monitoring terhadap parameter listrik yang ada pada sebuah transfromator distribusi telah berhasil dirancang dan diimplementasikan dengan baik. Pengujian keseluruhan alat dengan cara menggabungkan seluruh komponen yang akan digunakan meliputi PZEM-004T, ESP8266 dan juga software untuk perintah yaitu Arduino Ide dan software untuk menampilkan grafik sehingga sistem ini dapat digunakan untuk memonitoring tamu secara real time.

\section{DAFTAR PUSTAKA}

[1] D. Suswanto, Sistem Distribusi Tenaga Listrik, Padang: Universitas Negeri Padang, 2011.

[2] Syahputra, Transmisi Dan Distribusi Tenaga Listrik, Yogyakarta: LP3M UMY Yogyakarta, 2017. USTAKA

[3] Zuhal, Dasar Teknik Tenaga Listrik dan Elektronika Daya, Jakarta: PT Gramedia Pustaka Utama, 2013.

[4] . Aprianto, "Pemeliharaan Trafo Distribusi," Universitas Diponegoro, Semarang, 2012.

[5] I. Anggraeni, "Sistem Monitoring Penggunaan Daya Listrik Menggunakan Sensor Arus Berbasis Mikrokontroler AVR," Institut Teknologi Telkom, Bandung, 2012.

[6] K. Sari, "Monitoring Transformator Distribusi Berbasis Internet Of Things," Universitas Lampung, Bandar Lampung, 2019.

[7] R. Fachri, "Tutorial Arduino Mengukur Arus Dengan Modul Sensor Arus ACS712," Universitas Indonesia, Depok, 2016. 